\title{
Discontinuation of implants use and associated factors among women attending health facility clinics in Hawassa City, Southern Ethiopia, 2019; cross sectional study
}

\author{
Belay Amare Abebe ${ }^{1 *}$ and Mulu Reda Terefe ${ }^{2}$
}

\begin{abstract}
Background: Despite improving the availability and use of Implants, discontinuation is becoming a public health concern. A significant proportion of women discontinuing the service before its due date, which is of concern in the health system and its consequence may lead to a program failure. This might have also social and economic consequences for users. Only 8\% of married women in Ethiopia use implants. Apart from its low utilization, premature removal is common for unknown reasons. However, there is paucity of information on discontinuation of implants use and associated factors in the study area.
\end{abstract}

Objective: The study was aimed to assess discontinuation of implants use and associated factors among women attending health facility clinics in Hawassa city, southern Ethiopia, from March, 01-April, 01/2019.

Methods: Facility based cross sectional study design was used. Out of 16 health facilities, 9 of them were selected for this study using simple random sampling. Total sample size of this study was determined to be 351. Data were collected from study subjects using pretested, structured questionnaire through a face-to-face interview. Data was analyzed using descriptive statistics and logistic regression. The result is presented using the Crude Odds ratio as well as Adjusted Odds Ratio with the corresponding 95\% confidence level.

Result: Out of 351 study participants, the overall proportion of implants discontinuation was $49.3 \%(95 \% \mathrm{Cl}$ : $44.2-$ 55.0). Lack of counseling about side effects ( $A O R=2.394 ; 95 \% \mathrm{Cl}: 1.422-4.030$ ), developing side effects ( $\mathrm{AOR}=6.325$; 95\% Cl: $3.719-10.757)$ and lack of post insertion follow-up ( $\mathrm{AOR}=2.241 ; 95 \% \mathrm{Cl}: 1.186-4.234$ ) the major factors associated with discontinuation of Implants.

Conclusion and recommendation: In this study, the overall proportion of discontinuation of Implants among women who were using Implants was high. Health professionals could give pre-insertion counseling about side effects and post insertion dates for follow-up to improve of utilization of implants.

Keywords: Associative factors, Discontinuation, Implants

\footnotetext{
* Correspondence: gideteb60@gmail.com

'Department of Midwifery, College Medicine and Health Sciences, University of Hawassa, PO Box-1560, Hawassa, Ethiopia

Full list of author information is available at the end of the article
}

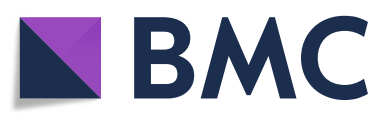

() The Author(s). 2020 Open Access This article is licensed under a Creative Commons Attribution 4.0 International License, which permits use, sharing, adaptation, distribution and reproduction in any medium or format, as long as you give appropriate credit to the original author(s) and the source, provide a link to the Creative Commons licence, and indicate if changes were made. The images or other third party material in this article are included in the article's Creative Commons licence, unless indicated otherwise in a credit line to the material. If material is not included in the article's Creative Commons licence and your intended use is not permitted by statutory regulation or exceeds the permitted use, you will need to obtain permission directly from the copyright holder. To view a copy of this licence, visit http://creativecommons.org/licenses/by/4.0/. The Creative Commons Public Domain Dedication waiver (http://creativecommons.org/publicdomain/zero/1.0/) applies to the data made available in this article, unless otherwise stated in a credit line to the data. 


\section{Backround}

Modern contraception is highly effective in preventing unintended pregnancy and reducing maternal mortality. Family planning (FP) is a process that usually involves a discussion between a woman, a man, and a trained family planning service provider focusing on family health and the desires of the couple to either limit or space their family size [1]. Contraceptives discontinuation is removal of the methods by the women due to any reason. Implants are long-acting and extremely effective at preventing pregnancy, with a clinical failure rate less than $1 \%$ [19].

Discontinuation of effective methods of contraception is a universal problem, though rates vary widely by population and country [8]. Every year, about one-third of the 182 million pregnancies occurring worldwide are unplanned [7, 21]. Globally, 33 million accidental pregnancies are estimated to occur among women reportedly using a contraceptive method, either traditional or modern [25].

Evidence from 60 demographic and health surveys conducted on causes and consequences of contraceptive discontinuation; on average, $38 \%$ of women discontinue using reversible methods by the 12 th month and $64 \%$ by the 36th month in 19 countries [25].

According to a report based on developing countries, Implanon discontinuation within the first year ranges from $2 \%$ in Nigeria to $23 \%$ in UK $[2,3]$.

Contraceptive discontinuation contributes to unplanned pregnancies, unwanted births and termination of pregnancies that expose a risk to the health of women. This unplanned pregnancy has impacts on larger family size and ultimately contributes to higher overall fertility rates which may result social, economic and physical health disabilities [18, 23].

According to [11], contraceptive discontinuation in the 5 years preceding the survey were $>35 \%$ within 12 months' use [11].

Only $8 \%$ of married women in Ethiopia use implants $[12,26]$. Apart from its low utilization, premature removal is common for unknown reasons. In addition, there is limited information on discontinuation of implants use and associated factors in the study area. Therefore, this study was aimed to assess discontinuation of implants use and associated factors among women attending health facility clinics in Hawassa city, Southern Ethiopia, from March, 01 to April, 01/2019.

The findings of this study will enhance the planning and decision-making capacity of health professionals to seek possible solutions to the problems of the community in collaboration with the stake holders concerned. In addition, the findings will help local programmer managers, planners and other concerning organizations working in the field of family planning and maternal health to plan new strategies and prepare training programs based on the identified factors to enhance retention of utilization in the community. Finally, this study will provide baseline data for other researchers to investigate a prospective future study in the field.

\section{Conceptual framework (Fig. 1) \\ Methods and materials \\ Study area and period}

Hawassa City Administration, is the capital city of Southern nation nationality people, and Sidama Zonal administration, located $275 \mathrm{~km}$ to the south of the capital city of Ethiopia, Addis Ababa. The city administration is divided in 8 sub cities, of which 7 are urban having 21 kebeles and one peri-urban with 12 kebeles with a total population of 387,087 in 2017 (CSA, 2017). The study was conducted in nine health facilities, i.e. HURH, AGH, Hawassa family guidance association, Hawassa Merry stop international clinic, Millinium $\mathrm{HC}$, Alamura $\mathrm{HC}$, Adare $\mathrm{HC}$, Tulla $\mathrm{HC}$ and Tilite $\mathrm{HC}$ of Hawassa City, Southern Ethiopia, from March, 01 to April 01/2019.

\section{Study design}

Facility based cross-sectional study was used.

\section{Study population}

All reproductive age women who were using Implants and came to the selected health institutions for contraceptives related reasons during the actual data collection period.

\section{Inclusion and exclusion criterias}

All reproductive age women who were using Implants and came to the selected health institutions for contraceptives related reasons during the actual data collection period were included in the study. Women who were unable to communicate and respond like hearing loss were excluded from the study.

\section{Sample size determination}

Outcome variable and various factors significantly associated with the outcome variable in previous studies were considered to determine the sample size. Accordingly, for the first and second specific objectives the sample size was calculated separately and the larger sample size was taken to be used for this study.

\section{Specific objective 1}

For magnitude of discontinuation of Implants.

The sample size was calculated by using single population proportion formula as follows. 


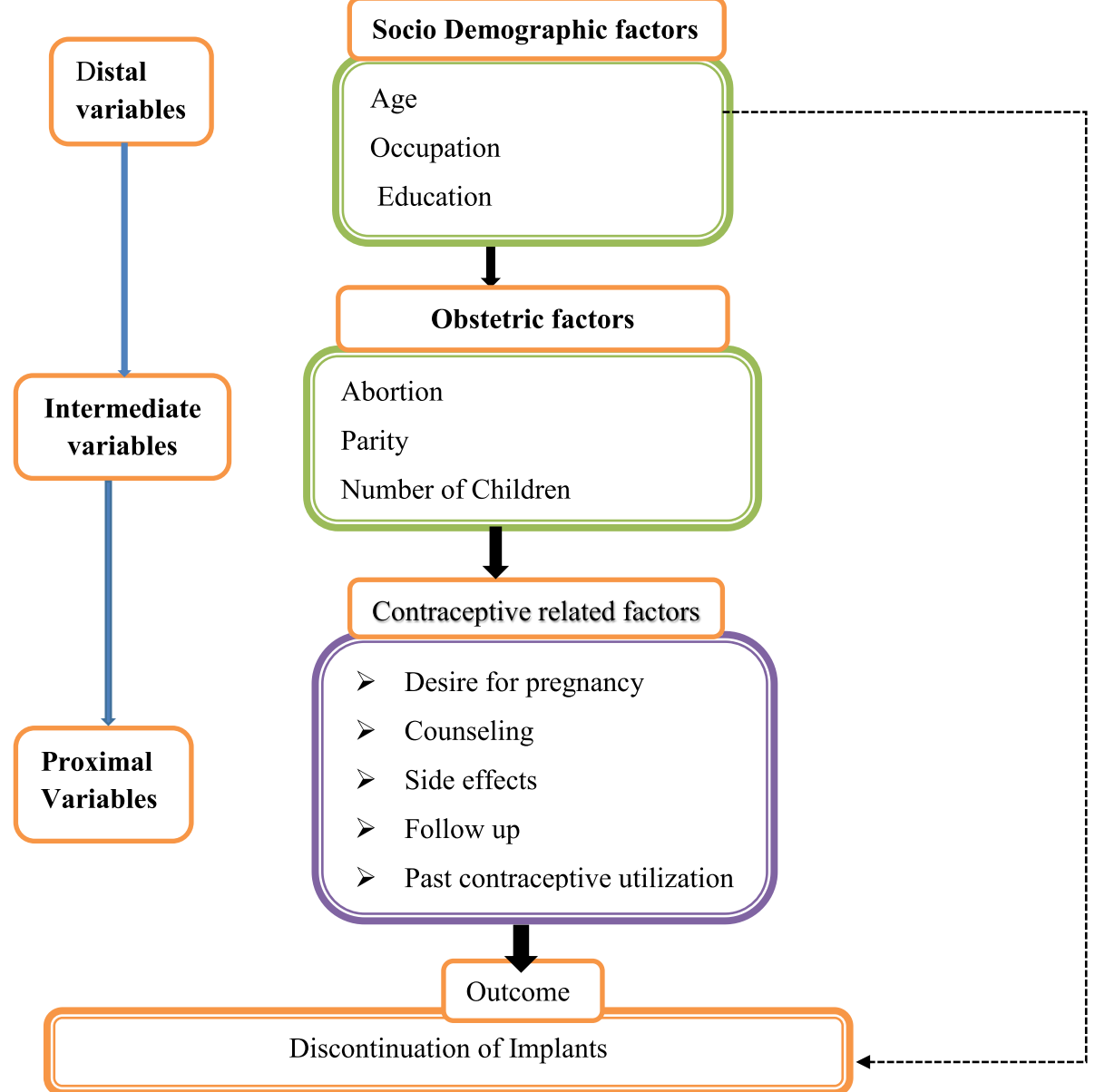

Fig. 1 Conceptual framework for the study on assessment of discontinuation of Implants and associated factors developed by principal investigator. This conceptual framework is developed from different literature used from a range of cross sectional and case control studies conducted on early discontinuation of use of Implanon and associated factors in Ethiopia $[6,15]$

$$
n=\frac{\left(z_{\alpha / 2}\right)^{2} \times p(1-p)}{d^{2}}
$$

Where $n$ is the minimum sample size required, $p$ is expected proportion of discontinued mothers, $z=1.96$ $(95 \% \mathrm{CI})$ and $d=0.05$ is the margin of error between the sample and the population. For this study $p=16 \%$, from study conducted on Ofla Tigray on the prevalence of discontinuation of implants and associated factors. Thus, applying the formula, by substituting these values into Eq. (1) gives, $=206.5$. By adding $10 \%$ non-response rate, the final sample size becomes 227 for the first specific objective.

\section{Specific objective 2}

factors associated with discontinuation of Implants.

The sample size of the second specific objective of this study was calculated by considering factors that were significantly associated with the outcome variable, two sided confidence level of $95 \%$, the margin of error of $5 \%$, power by $80 \%$ and the ratio of exposed to unexposed 1:1 using Epi-Info Version 7 software.

As it can be seen from Table 1, the calculated sample size of the second objective is larger than that of the first objective. By adding $10 \%$ non-response rate, $n=313^{*} 0.1+$ $313=351$

\section{Sampling technique / procedure}

Out of the 16 health facilities available in Hawassa city administration, both hospitals (i.e. HURH and Adare General Hospital), five HCs, (i.e. Millinium, Adare, Tilite, Tulla and Alamura HCs) and two NGO clinics (i.e. Hawassa family guidance association and Hawassa Marie stops international) were randomly selected for this study using lottery method.

In order to ensure a proportionate allocation of the total sample size determined, the average six-month client flows of each selected health facility were considered prior to the start of data collection. The study subjects were identified based on the information obtained from 
Table 1 Sample size determination for magnitude and associated factors of Implants discontinuation among Implants user women in health facilities of Hawassa city, Southern Ethiopia, 2018/19

\begin{tabular}{lllll}
\hline Associated factors & Exposed outcome \% & Unexposed outcome \% & Sample size & Reference \\
\hline Removal due to side effect & 75.6(side effect faced) & 60.2(side effect not faced) & 313 & [15] \\
Follow up & 35.9(had follow up) & 15.76(hadn't follow up) & 166 & [22] \\
\hline
\end{tabular}

the client card. The information obtained from the 6 Months enrollment record (June-December/2018) from the family planning registry books showed that a total of 3500 women were used Implants within 6 months in the selected institutions.

As the result, the average six-months client flow for HURH, AGH, Hawassa family guidance association, Hawassa Marie stops international clinic, Millinium HC, Alamura HC, Adare HC, Tulla HC and Tilite $\mathrm{HC}$ was 500, $560,440,400,310,380,300,360$, and 250 respectively.

So that, sample was proportionally allocated for each selected institution. Data collectors approached and recruited implants user women who came to the selected clinics due to contraceptives related reasons. Every woman was included in the study until the required sample size was met in each health facility (Fig. 2).

\section{Data collection methods}

\section{Data collection instruments}

The data for this study was collected using pre-tested, structured questionnaire through a face to face interview. The tool for this study is adopted from previous literature of similar studies $[6,15]$. The questionnaire contains three main parts. These are; socio-demographic characteristics, Obstetric related factors and contraceptive methods related variables.

\section{Data collectors}

Nine Nurses and Midwives with a qualification of degree were the data collectors. Three supervisors supervised and provided all items necessary for data collection on each data collection day for data collectors.

\section{Data collection procedure}

Data were collected from study subjects using pretested, structured questionnaire through a face-to-face interview. The questionnaire was developed in English and translated into Amharic and then back to English to check for its consistency. The instrument was adopted from different literature developed for similar purposes by different authors $[6,15]$. The interviewers were Midwives and Nurses with a qualification of degree. The responsibility of the data collectors was to fill the questionnaire after obtaining informed, voluntary, written and signed consent of the study subjects. The principal investigator and supervisors supervised and provided

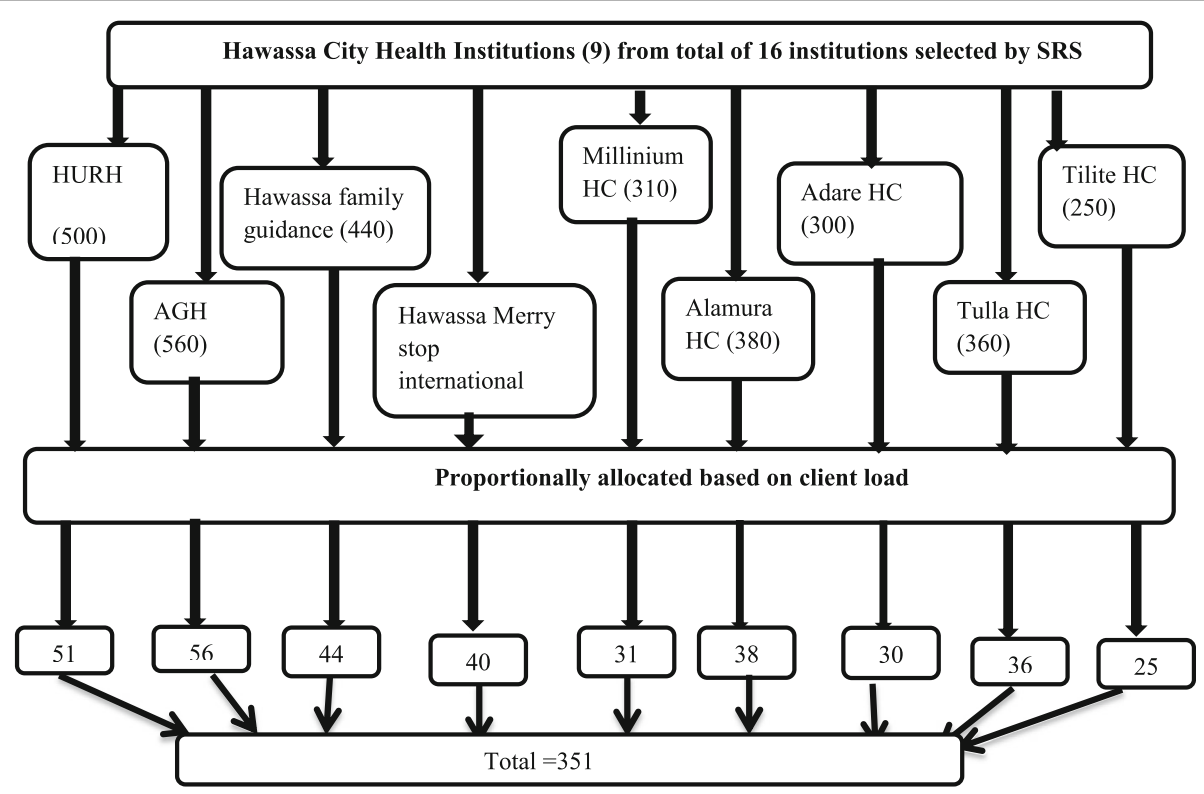

Fig. 2 Schematic presentation of sampling procedure for the study on discontinuation of implants and associated factors developed by principal investigator. Six months' enrollment in Heath institutions of Hawassa city administration in both public hospitals, five HCs and two NGO clinics from family planning registration book, for sample selection (June-December/2018) 
Table 2 Socio-demographic characteristics of the study participants in health facilities of Hawassa city, Southern Ethiopia, $2019(n=351)$

\begin{tabular}{|c|c|c|}
\hline Variables & Frequency & Percentage \\
\hline \multicolumn{3}{|l|}{ Women's age } \\
\hline $19-24$ & 100 & 28.5 \\
\hline $25-29$ & 164 & 46.7 \\
\hline $30-34$ & 69 & 19.7 \\
\hline$=>35$ & 18 & 5.1 \\
\hline \multicolumn{3}{|l|}{ Marital status } \\
\hline Single & 8 & 2.3 \\
\hline Married & 343 & 97.7 \\
\hline \multicolumn{3}{|l|}{ Religion } \\
\hline Orthodox & 103 & 29.3 \\
\hline Muslim & 20 & 5.7 \\
\hline Protestant & 218 & 62.1 \\
\hline Catholic & 9 & 2.6 \\
\hline Others & 1 & 3 \\
\hline \multicolumn{3}{|l|}{ Ethnicity } \\
\hline Sidama & 146 & 41.6 \\
\hline Wolayta & 82 & 23.4 \\
\hline Amhara & 62 & 17.7 \\
\hline Gurage & 25 & 7.1 \\
\hline Oromo & 14 & 4.0 \\
\hline Others* & 22 & 6.3 \\
\hline \multicolumn{3}{|l|}{ Occupation } \\
\hline House wife & 149 & 42.5 \\
\hline Merchant & 62 & 17.7 \\
\hline Private employee & 47 & 13.4 \\
\hline Government employee & 65 & 18.5 \\
\hline Student & 28 & 8.0 \\
\hline \multicolumn{3}{|l|}{ Maternal educational status } \\
\hline Unable to read and write & 44 & 12.5 \\
\hline Read and Write & 39 & 11.1 \\
\hline Primary & 99 & 28.2 \\
\hline Secondary & 82 & 23.4 \\
\hline College and above & 87 & 24.8 \\
\hline \multicolumn{3}{|c|}{ Husband educational status ( $n=343$ ) } \\
\hline Unable to read and write & 24 & 7.0 \\
\hline Read and Write & 23 & 6.7 \\
\hline Primary & 55 & 16.0 \\
\hline Secondary & 100 & 29.2 \\
\hline College and above & 141 & 41.1 \\
\hline \multicolumn{3}{|c|}{ Husband's occupation ( $n=343$ ) } \\
\hline Farmer & 21 & 6.1 \\
\hline Merchant & 123 & 35.9 \\
\hline
\end{tabular}

Table 2 Socio-demographic characteristics of the study participants in health facilities of Hawassa city, Southern Ethiopia, 2019 ( $n=351)$ (Continued)

\begin{tabular}{lll}
\hline Variables & Frequency & Percentage \\
\hline Private employee & 59 & 17.2 \\
Government employee & 123 & 35.9 \\
Student & 7 & 2.0 \\
Others & 10 & 2.9 \\
\hline
\end{tabular}

all items necessary for data collection on each data collection day, checking filled questionnaire for completeness and logical consistency and solve problems forwarded during the time of data collection.

\section{Data quality assurance}

To assure the quality of data, properly designed data collection tools were used. Training was given for data collectors and supervisors about research objectives, data collection tools, procedures and interview techniques for 1 day. The principal investigator, together with three supervisors, supervised techniques of data collection and completeness of the tools on the daily basis to give an appropriate feedback accordingly. Data double entry was done to make comparisons of two data clerks and resolved some difference.

\section{Pre-test}

Before the actual data collection period, the questionnaire was tested on $5 \%$ of the total sample size (351) on 18 reproductive age women who used implants at noneselected health facilities to check the context of data. After pretest, the questionnaire was revised and amended per necessary.

\section{Data processing and analysis}

After data collection, the questionnaire was checked for completeness and data entry was made using EPI DATA V-3.1 and then exported to the Statistical Package for Social Science [SPSS] V-22 computer software for analysis. Descriptive statistics and bivariate analysis were performed. Variables with $p$-value $<0.25$ in bivariate analysis were planned to be entered in multivariate logistic regression analysis. Multi co-linearity test was carried out to check the linear correlation among independent variables by using standard error and co-linearity statistics. Variance inflation factor $>10$ and standard error $>2$ were considered as suggestive of the existence of multi co-linearity. Therefore, variables with Variance inflation factor $>10$ and/ standard error $>2$ were checked to be dropped. Hosmer -Lemeshow goodness- of- fit was used to check model fitness. Omnibus test was significant and Hosmer- Lemeshow's test was found to be insignificant which indicate that the model was fitted. Based on the 
Table 3 Obstetrics related factors for discontinuation of implants among implants user women in health facilities of Hawassa city, Southern Ethiopia, $2019(n=351)$

\begin{tabular}{lll}
\hline Variables & Frequency & Percentage \\
\hline Parity & 28 & \\
0 & 207 & 8.0 \\
$1-2$ & 116 & 59.0 \\
$3+$ & & 33.0 \\
Number of living children & 29 & \\
0 & 226 & 8.3 \\
$1-2$ & 86 & 64.4 \\
$3-4$ & 10 & 24.5 \\
$5+$ & & 2.8 \\
History of abortion & 107 & \\
Yes & 244 & 30.5 \\
No & & 69.5 \\
Desire for pregnancy & 239 & 68.1 \\
Yes & 112 & 31.9 \\
No & 94 & 39.3 \\
When they want to become pregnant( $\boldsymbol{n}=\mathbf{2 3 9 )}$ & 60.7 \\
Within two years & 145 & \\
After two years & & \\
\hline
\end{tabular}

findings of bivariate analysis, variables with $p$-value $<$ 0.25 were entered into multivariate logistic regression analysis with $95 \%$ confidence level and 5\% significant level. AOR with $95 \% \mathrm{CI}$, and level of significant at $p$ value $<0.05$ was considered. Variables with $p$-value less than 0.05 in the multivariate logistic regression analysis were considered as statistically significant with implants discontinuation.

\section{Result}

\section{Socio-demographic characteristics}

All study participants had responded to the questionnaire, making a response rate of $100 \%$. The range of study participants' age was between 19 and 44 years with mean $( \pm \mathrm{SD})$ age $26.6 \pm 4.3$. Out of the total respondents, $164(46.7 \%)$ of women were in the age range of 25-29. Three hundred forty three $(97.7 \%)$ of participants were married and about 218 (62.1\%) were Protestant followed by Orthodox, 103 (29. 3\%) in religion. One hundred forty six (41.6\%), of participants were Sidama in Ethnicity.

Among the participants, 149 (42.5\%) were housewives and 166 (38.5\%) of their husbands were merchants by occupation. Ninety nine (28.2\%) of the participants were at primary level and 141 (41.1\%) of their husbands were college and above in educational status (Table 2).

\section{Obstetrics related characteristics}

Two hundred and seven (59.0\%) respondents had given birth one to two times while $116(33.0 \%)$ of the participants gave birth more than three times. Among the participants who gave birth, 226 (64.4\%) women had one to two alive children. Two hundred and forty-four (69.5\%) of participants had no history of abortion and 239 (68.1\%) women had desire for another pregnancy. Out of those who had desire for another pregnancy, 94 (39.3\%) and 145 (60.9\%) women desired to become pregnant within two and after two years respectively (Table 3).

\section{Contraceptive related characteristics}

In this study, 261 (74.4\%) and 90 (25.6\%) of participants were Implanon and Jaddle users respectively. Three hundred and thirty $(65.5 \%)$ of study participants had ever used contraceptives before the implant they were using during the study period. Out of them 176 (76.5\%) had used injectable followed by oral contraceptive pills 83 (36.1\%). Of the total participants, 305(87\%) women got the implant insertion from government institutions and $252(71.8 \%)$ of them chose the contraceptives by their own.

Three hundred and twenty-seven (93.2\%) and 165 (47.0\%) of the participants got counseling service about the benefit and side effect of implants during insertion respectively. Two hundred and seventy-five (78.3\%) of study participants had an appointment for follow-up during their implant utilization period. One hundred and thirty-six (38.7\%) of the study participants had ever faced side effects during their implants utilization period. The suggested reasons for discontinuation of implants were identified that side effect was the major, which accounted 79 (45.7\%) followed by $41(23.7 \%)$ of method switching after service end (Table 4).

Among participants who discontinued implants due to non-side effect reasons, method switching after service accounted 41 (23.7\%) followed by desire for another pregnancy, 40 (23.1\%) and others like husband go abroad, husband's objection, divorce and health concern accounted about 13 (7.5\%). Whereas, among women who discontinued implants due to side effects, menstrual disruption accounted 56 (70.0\%) followed by 19 (23.8\%) weight gain (Fig. 3).

\section{Magnitude of implants discontinuation}

From 351 study participants, 49.3\% (95\% CI: 44.2, $55.0 \%)$ was overall proportion of Implants discontinuation (Fig. 4). The mean $( \pm \mathrm{SD})$ overall duration of Implants utilization in years was $2.2 \pm 1.1$. 
Table 4 Contraceptives related characteristics for discontinuation of implants in Health facilities of Hawassa city, Southern Ethiopia, $2019(n=351)$

Variables
Type of implant used by participants
Implanon
Jaddle

Frequency Percentage

Ever used contraceptives before implant

No

$261 \quad 74.4$

90

25.6

Type of contraceptive used before implant

OCP
Injectable
IUCD
Implants

Place of insertion of the method

Hospital

Health center

Health post

Family guidance

Others*

Counseling for benefit of implants

$\begin{array}{lll}\text { Yes } & 327 & 93.2 \\ \text { No } & 24 & 6.8 \\ \text { Counseling for side effects of implants } & & \\ \text { Yes } & 165 & 47.0 \\ \text { No } & 186 & 53.0\end{array}$

Estimation of information participants get during counseling (satisfaction)

No

Have you ever faced side effects

Yes

No

Who choose implant

Own choice

My husband

Health professional

Health extension

My neighbor

Reasons to choose the method

$$
\begin{aligned}
& \text { Safety } \\
& \text { Long protection } \\
& \text { It can remove at any time } \\
& \text { Immediate fertility return }
\end{aligned}
$$

Follow-up
Table 4 Contraceptives related characteristics for discontinuation of implants in Health facilities of Hawassa city, Southern Ethiopia, 2019 ( $n=351)$ (Continued)

\begin{tabular}{lll}
\hline Variables & Frequency & Percentage \\
\hline Yes & 275 & 78.3 \\
No & 76 & 21.7 \\
Removal due to side effect $(n=221)$ & & \\
Yes & 79 & 35.7 \\
No & 142 & 64.3 \\
\hline Others* Merry stopes international clinic, private hospitals and clinics
\end{tabular}

Factors associated with implants discontinuation

Findings from bivariate analysis resulted that, participants' occupational status, maternal educational status, Husband educational status, past contraceptive utilization, lack of counseling about possible benefits, lack of counseling about side effects, lack of appointment for follow-up and developing side effects were associated with discontinuation of implants at $p$-value $<$ 0.25 . However, in a multivariate logistic regression analysis, lack of counseling about side effects $(\mathrm{AOR}=2.394$; 95\% CI: 1.422-4.030), lack of appointment for follow up (AOR $=2.241 ; 95 \%$ CI: 1.186-4.234) and developing side effects $(\mathrm{AOR}=6.325 ; 95 \% \mathrm{CI}: 3.719-10.757)$ were found significantly associated with implants discontinuation (Table 5).

\section{Discussion}

The proportion of implants discontinuation among women who were users of implants was high. Factors such as lack of counseling about side effects, developing side effects and lack of appointment for follow up were significantly associated with discontinuation of implants.

The proportion of implants discontinuation among implants user women was $49.3 \%$. This finding is in line with studies conducted in Netherland, 47\% [23], Jordan, 45\%(USAID, 2007-2009) and Cambodia, 45\% [21]. However, the current proportion is lower than study conducted in Australia, 60\% [13] and at Debre Tabor 65\% [15]. This result variation might be due to study nature of study participants. In studies conducted in Australia and Debre Tabor, the study participants were both urban and rural, but urban only in this study. As a result, awareness towards the behaviors of contraceptives might be better at urban residents. Moreover, it might be due to efforts made by health providers to improve the retention of utilization.

The current proportion is also higher than studies conducted in the United States, 25.2\% [10], Pakistan, 18.0\%, Egypt, 36\%, Yemen, 43\%, [21], Ilorin, Nigeria, 26.5\% [4], Abakaliki, southeast Nigeria, 29.6\% [14] and at Ofla Tigray, $16 \%$, [6]. The difference might be due to lack of pre-insertion counseling of side effects of the 
$70.0 \%$

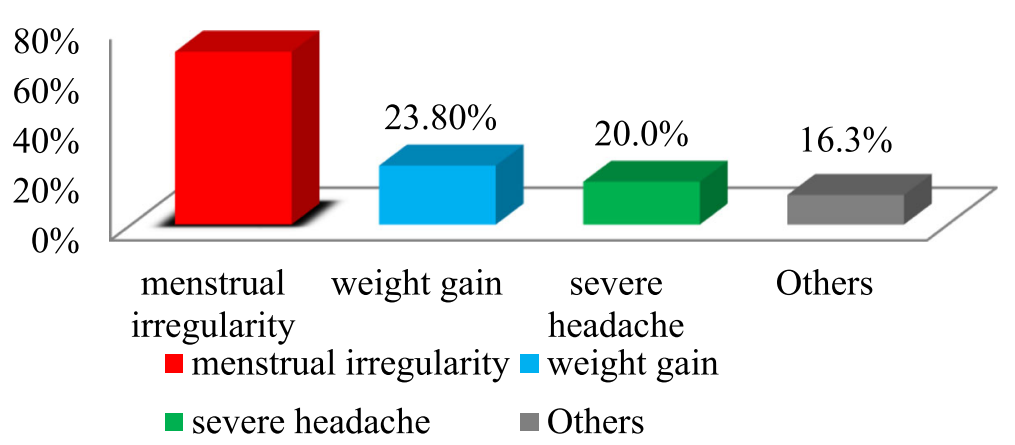

Fig. 3 The main side effects for discontinuation of implants among implants user women in health facilities of Hawassa city administration, Southern Ethiopia, 2019. Others*: Insertion arm pain, achene, weight reduction and difficult to work

methods as compared to other studies (USAID, 20072009). In addition to this, it might be due to lack of appointment for follow up as compared to other studies [4, $10,21,23]$. The other reason for differences in current proportion might be due to higher sample size of the current study compared to other studies $[6,10,14]$. Another possible reason might be due to sociocultural differences of respondents across the study areas.

This study showed that women who didn't get preinsertion counseling service about side effects were 2.4 times more likely to discontinue than those who got counseling services. This is consistent with study conducted in Tigray [6], Debre Tabor [15], Jordan, India [5], Diguna Fango [22] and Philippines [20]. Providing counseling about side effects of implants was positively associated with use of the methods [20, 22]. So, the possible justification of this factor might be due to lack of pre-placement counseling and support by the service providers to help women continue on contraception. In addition, sociocultural variations, lack of skilled counselor, outlook and level of understanding of participants towards the contraceptives might be the reasons that made the factor associated with discontinuation of the implants.

According to this study, the likelihood of discontinuing implants among women who developed side effects was 6.3 times higher than those who did not face side effect. This is consistent with studies conducted in Ankara, Turkey, Abakaliki, southeast Nigeria [14], Debre Tabor [15], Arsi, Oromia region [9], Jos, Nigeria [16], Tigray [6], Nepal [24] and Jordan. The possible reasons might be exposing to side effect of the method could contribute for discontinuation of the contraceptives. In addition, respondents who discontinued implants due to side effects may be due to intolerance of side effects and fears that different complications will occur in their health in the future.

This study also revealed that, the odds of discontinuation of implants among women who lacked post insertion follow up were 2.2 times higher than those who had

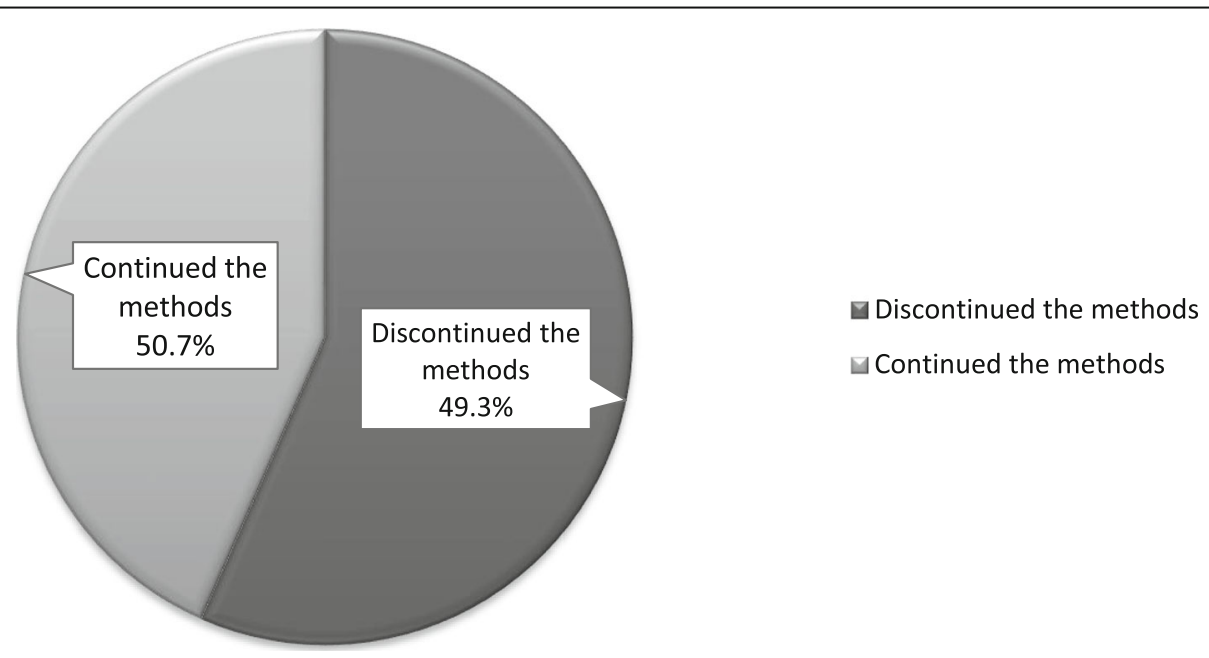

Fig. 4 Proportion of implants discontinuation among implants user women in health facilities of Hawassa city administration, Southern Ethiopia, 2019 
Table 5 Factors associated with implants discontinuation among implants user women in health facilities of Hawassa city, Southern Ethiopia, $2019(n=351)$

\begin{tabular}{|c|c|c|c|c|}
\hline \multirow{2}{*}{$\begin{array}{l}\text { Variables } \\
\text { Occupation of participant }\end{array}$} & \multicolumn{2}{|c|}{$\begin{array}{l}\text { LARCs discontinuation } \\
\text { Ye s (\%) No (\%) }\end{array}$} & \multirow[t]{2}{*}{$P$-value } & \multirow[t]{2}{*}{$\begin{array}{l}\text { AOR } \\
(95 \% \text { C.I) }\end{array}$} \\
\hline & & & & \\
\hline House wife & 71 (47.7\%) & $78(52.3 \%)$ & 0.110 & $2.622(0.855-8.041)$ \\
\hline Merchant & $30(48.4 \%)$ & $32(51.6 \%)$ & 0.164 & $2.613(0.801-8.529)$ \\
\hline Private employee & $27(57.4 \%)$ & $20(42.6 \%)$ & 0.559 & $1.531(0.456-5.141)$ \\
\hline Government employee & $32(49.2 \%)$ & $33(50.8 \%)$ & 0.184 & $2.337(0.71-7.694)$ \\
\hline Student & $18(64.3 \%)$ & $10(35.7 \%)$ & & 1 \\
\hline \multicolumn{5}{|l|}{ Maternal Educational status } \\
\hline Unable to read and write & $22(50.0 \%)$ & $22(50.0 \%)$ & 0.663 & $1.423(0.360-5.633)$ \\
\hline Read and Write & $23(59.0 \%)$ & $16(41.0 \%)$ & 0.605 & $0.798(0.235-2.712)$ \\
\hline Primary & $42(42.4 \%)$ & $57(57.6 \%)$ & 0.115 & $2.240(0.793-6.329)$ \\
\hline Secondary & $44(53.7 \%)$ & $38(46.3 \%)$ & 0.962 & $1.095(0.427-2.811)$ \\
\hline College and above & $47(54.0 \%)$ & $40(46.0 \%)$ & & 1 \\
\hline \multicolumn{5}{|l|}{ Husband's educational level } \\
\hline Unable to read and write & $13(48.1 \%)$ & $14(51.9 \%)$ & 0.708 & $0.581(0.159-2.1177)$ \\
\hline Read and Write & $15(60.0 \%)$ & $10(40.0 \%)$ & 0.465 & $0.351(0.112-1.118)$ \\
\hline Primary & $31(56.4 \%)$ & $24(43.6 \%)$ & 0.589 & $0.446(0.189-1.052)$ \\
\hline Secondary & $44(44.0 \%)$ & $56(56.0 \%)$ & 0.215 & $0.903(0.444-1.836)$ \\
\hline College and above & $75(52.1 \%)$ & $69(47.9 \%)$ & & 1 \\
\hline \multicolumn{5}{|c|}{ Ever used contraceptives before implants } \\
\hline Yes & $106(46.1 \%)$ & $124(53.9 \%)$ & 0.017 & $1.613(0.940-2.769)$ \\
\hline No & $72(59.5 \%)$ & 49 (40.5\%) & & 1 \\
\hline \multicolumn{5}{|c|}{ Counseling about side effects of implants } \\
\hline Yes & $108(65.5 \%)$ & $57(34.5 \%)$ & $<0.0001$ & $2.394(1.422-4.03) * *$ \\
\hline No & $70(37.6 \%)$ & $116(62.4 \%)$ & & 1 \\
\hline \multicolumn{5}{|c|}{ Counseling about benefit of implants } \\
\hline Yes & $171(52.3 \%)$ & $156(47.7 \%)$ & & 1 \\
\hline No & $7(29.2 \%)$ & $17(70.8 \%)$ & 0.034 & $2.312(0.825-6.480)$ \\
\hline \multicolumn{5}{|l|}{ Side effects } \\
\hline Yes & $34(25.0 \%)$ & $102(75.0 \%)$ & $<0.0001$ & $6.33(3.719-10.76) * * *$ \\
\hline No & $144(67.0 \%)$ & $71(33.0 \%)$ & & 1 \\
\hline \multicolumn{5}{|l|}{ Follow-up } \\
\hline Yes & $155(56.4 \%)$ & $120(43.6 \%)$ & & 1 \\
\hline No & $23(30.3 \%)$ & $53(69.7 \%)$ & $<0.0001$ & $2.241(1.186-4.234)$ * \\
\hline
\end{tabular}

Significant at ${ }^{* *} p<0.0001,{ }^{* *} p=0.001,{ }^{*} p=0.013$, AOR Adjusted odds ratio

appointment for follow up. This is in line with studies conducted in Port, Nigeria [17] and Diguna Fango [22]. It might be due to the fact that post insertion follow-up increases retention of utilization, client trust on health providers, and knowledge about the overall behaviors of the contraceptives via participants.

This study includes nine health facilities (multicenter study) which increase external validity of the study.
Recall bias was not challenging unlike studies conducted on ever used participants.

The study was conducted in an urban health institution setting, though the majority of the population lives in rural setting.

\section{Conclusion}

In this study, the overall proportion of discontinuation of implants was high (49.3\%). Out of the overall 
proportion of discontinuation, reason of side effects and husband objection accounted $23.4 \%$. Factors like lack of counseling about side effects, developing side effects and lack of post insertion follow-up were found statistically significant with implants discontinuation.

\section{Strengths}

Recall bias was not challenging unlike studies conducted on ever used participants.

\section{Limitation}

The study was conducted in an urban health institution setting, though the majority of the population lives in rural setting.

\section{Recommendations}

Health organizations and other stake holders better to work on health care providers at enabling them to give appropriate pre-insertion counseling and post insertion date of follow-up in order to increase the retention of utilization.

Health professionals could give pre-insertion counseling with giving emphasis on possible side effects of implants.

Early side effects management and reassurance is recommended to decrease discontinuation and improve the retention of utilization of implants.

In addition to this, health providers could give post insertion date of follow-up for their clients.

\section{Abbrivations \\ AOR: Adjusted odds ratio; BDHS: Bangladesh Demographic Health Survey; COR: Crude odds ratio; CSA: Central Statistical Agency; EDHS: Ethiopia Demographic Health Survey; EFMOH: Ethiopian Federal Ministry of Health FHI: Family Health International; HURH: Hawassa University Referral Hospital; ICF: International classification of functioning, disability and health; IUCD: Intra uterine contraceptive device; JPFHS: Jordan Population and Family Health survey; MDGs: Millinium development goals; OPDs: Out- Patient Department; SNNPRS: Southern Nation Nationality People's Representative state; SDG: Sustainable development goals; UK: United Kingdom; USAID: United States Agency of International Development; WHO: World Health Organization}

\section{Acknowledgments}

First of all, we would like to express our gratitude to the Hawassa City Health Office for giving us the opportunity to study in the city.

Secondly, we would like to express our deepest gratitude to Dr. Bezatu M. for his endless support and constructive comments throughout this paper development

Finally, we would like to thank those who hold our hands throughout the work (participants, data collectors, supervisors, family and colleagues).

\section{Authors' contributions}

Proposal developments, data collection, analysis, interpretation of results and discussion as well as manuscript preparation were processed by BA. MR had participated in data collection, supervision, analyzed data and advising throughout this paper development. Finally all Authors read and approved the manuscript.

\section{Funding}

No funding and sponsorship organization.
Availability of data and materials

Data and materials are fully available.

\section{Ethics approval and consent to participate}

The study was approved by the Haramaya University, College of Health and Medical Sciences Institutional Health Research Ethics Review Committee (IHRERC). The permission and agreement, consent was obtained from Southern Nations, Nationalities and Peoples Regional Health Bureau, Hawassa city health department and heads of the selected health facilities prior to the study period. Informed, voluntary, written and signed consent was taken from facility's head and participants before data collection started. The participants were also informed as their responses could not result in any harm to them and offer full rights and freedom to take part in the study or not to participate. The participant's name did not appear on data collection tool and confidentiality was maintained.

\section{Consent for publication}

Not applicable.

\section{Competing interests}

No competing interest at all.

\section{Author details}

${ }^{1}$ Department of Midwifery, College Medicine and Health Sciences, University of Hawassa, PO Box-1560, Hawassa, Ethiopia. ²Department Statistics, College of Natural and Computational Science, University of Hawassa, PO Box-1560, Hawassa, Ethiopia.

Received: 15 June 2020 Accepted: 17 September 2020

Published online: 23 October 2020

\section{References}

1. Alemayehu M, Belachew T, Tilahun T. Factors associated with utilization of Long acting and permanent contraceptive methods among married women of reproductive age in Mekelle town, Tigray region, North Ethiopia. BMC Pregnancy Childbirth. 2012;12:6.

2. Ali MM, Park MH, Ngo TD. Levels and determinants of switching following intrauterine device discontinuation in 14 developing countries. Contraception. 2014;90:47-53.

3. Ali MM, Sadler RK, Cleland J, Ngo TD, Shah $\Vdash H$. Long-term contraceptive protection discontinuation and switching behavior. Intrauterine device (lud) use dynamics in 14 developing countries; 2011.

4. Balogun O, Olaomo N, Adeniran A, Fawole A. Implanon sub-dermal implant: an emerging method of contraception in Ilorin, Nigeria. J Med Biomed Sci. 2014;3:1-5.

5. Bhatia P, Nangia S, Aggarwal S, Tewari C. Implanon: subdermal single rod contraceptive implant. J Obstetr Gynecol India. 2011;61:422.

6. Birhane K, Hagos S, Fantahun M. Early discontinuation of Implanon and its associated factors among women who ever used Implanon in Ofla District, Tigray, northern Ethiopia. Int J Pharma Sci Res. 2015;6:544-51.

7. Blumenthal P, Voedisch A, Gemzell-Danielsson K. Strategies to prevent unintended pregnancy: increasing use of Long-acting reversible contraception. Hum Reprod Update. 2010;17:121-37.

8. Bradley SE, Schwandt H, Khan S. Levels, Trends, And Reasons for Contraceptive Discontinuation. Dhs Anal Stud. 2009;20.

9. Burusie A. Reasons for premature removal of Implanon among users in Arsi zone, Oromia region, Ethiopia. Reprod Syst Sex Dis. 2015;4.

10. Casey PM, Long ME, Marnach ML, Bury JE. Bleeding related to Etonogestrel subdermal implant in a us population. Contraception. 2011;83:426-30.

11. EDHS 2016. Contraceptive discontinuation in the 5 years preceding the survey. Retrieved from https://dhsprogram.com/pubs/pdf/FR328/FR328.pdf: Accessed on 15/11/2018.

12. Gebremedhin S. Trend and socio-demographic differentials of caesarean section rate in Addis Ababa, Ethiopia: analysis based on Ethiopia demographic and health surveys data. Reprod Health. 2014;11:14.

13. Harvey C, Seib C, Lucke J. Continuation rates and reasons for removal among Implanon ${ }^{\oplus}$ users accessing two family planning clinics in Queensland, Australia. Contraception. 2009;80:527-32.

14. Igwe N. Intrauterine contraceptive device use in Abakaliki, Southeast Nigeria: a 5-year review. Trop J Med Res. 2016;19:138. 
15. Melkamu Asaye M, Syoum Nigussie T, Mequannt Ambaw W. Early Implanon discontinuation and associated factors among Implanon user women in Debre Tabor town, public health facilities, Northwest Ethiopia, 2016. Int J Reprod Med. 2018, 2018

16. Muthir J, Nyango D. Indications for removal of Etonogestrel implant within two years of use in Jos, Nigeria. East Afr Med J. 2010;87.

17. Ojule J, Oranu E, Enyindah C. Experience with Implanon in southern Nigeria. J Med Med Sci. 2012;3:710-4.

18. Ott, M. A. \& Sucato, G. S. 2014. Contraception for adolescents. Pediatrics, Peds 2014-2300.

19. Rademacher, K. H., HL Vahdat, L. \& Dorflinger, D. HO., And M.J. Steiner. 2014 "Global Introduction Of A Low-Cost Contraceptive Implant." In Critical Issues In Reproductive Health, Edited By A Kulczycki, . Netherlands: Springer. . 285-306.

20. Ramarao S, Lacuesta M, Costello M, Pangolibay B, Jones $H$. The link between quality of care and contraceptive use. Int Fam Plan Perspect. 2003:76-83.

21. Staveteig S, Mallick L, Winter R. Uptake and discontinuation of Long-acting reversible contraceptives (Larcs) in low-income countries; 2015.

22. Tadesse, A., Kondale, M., Agedew, E., Gebremeskel, F., Boti, N. \& Oumer, B. 2017. Determinant of Implanon discontinuation among women who ever used Implanon in Diguna Fango District, Wolayta Zone, Southern Ethiopia: A Community Based Case Control Study. International Journal of Reproductive Medicine, 2017.

23. Teunissen AM, Grimm B, Roumen FJ. Continuation rates of the subdermal contraceptive Implanon ${ }^{\oplus}$ and associated influencing factors. Eur J Contracept Reprod Health Care. 2014;19:15-21.

24. Thapa S. Early discontinuation of intrauterine device in Nepal-a retrospective study. WHO South-East Asia J Public Health. 2012;1:309.

25. WHO 2012. Causes and consequences of contraceptive discontinuation: evidence from 60 Demographic and Health Surveys. Retrieved from https:// www.who.int/reproductivehealth/publications/family_planning/9789241504 058/en/ : Accessed on 20/11/2018

26. Yalew SA, Zeleke BM, Tefera AS. Demand for Long acting contraceptive methods and associated factors among family planning service users, Northwest Ethiopia: a health facility based cross sectional study. BMC Res Notes. 2015;8:29.

\section{Publisher's Note}

Springer Nature remains neutral with regard to jurisdictional claims in published maps and institutional affiliations.

Ready to submit your research? Choose BMC and benefit from:

- fast, convenient online submission

- thorough peer review by experienced researchers in your field

- rapid publication on acceptance

- support for research data, including large and complex data types

- gold Open Access which fosters wider collaboration and increased citations

- maximum visibility for your research: over $100 \mathrm{M}$ website views per year

At $\mathrm{BMC}$, research is always in progress.

Learn more biomedcentral.com/submissions 